\title{
Information resources and latest news about Ebola virus disease available from ECDC
}

Eurosurveillance editorial team (eurosurveillance@ecdc.europa.eu) ${ }^{1}$

1. European Centre for Disease Prevention and Control (ECDC) Stockholm, Sweden

Citation style for this article:

Eurosurveillance editorial team. Information resources and latest news about Ebola virus disease available from ECDC. Euro Surveill. $2014 ; 19(31)$ :pii=20871.

Available online: http://www.eurosurveillance.org/ViewArticle.aspx?Articleld=20871

Article published on 07 August 2014

The European Centre for Disease Prevention and Control (ECDC) has a health topic page dedicated to providing comprehensive information about the Ebola virus disease (EVD) outbreak in West Africa [1]. The page links to public health advice and the ECDC risk assessment on EVD. The Centre has published information to travellers, available in 22 European Union languages, as well as epidemiological updates.

The EVD outbreak is evolving in West Africa since December 2013. The outbreak is centred to Guinea, Liberia and Sierra Leone and intensified during June and July 2014. A total of 108 new cases of EVD (laboratory-confirmed, probable and suspect) and 45 deaths were reported from Guinea, Liberia, Sierra Leone and Nigeria between 2 and 4 August 2014, bringing the total number of cases to 1,711 with 932 deaths [2].
The European Centre for Disease Prevention and Control is monitoring the development of the outbreak closely and evaluates the risk of importation of the disease to the EU, the risk of spreading, as well as the risk to EU travellers and residents in the affected areas in West Africa continuously.

\section{References}

1. European Centre for Disease Prevention and Control (ECDC). Stockholm: ECDC; August 2014. Available from: http://www. ecdc.europa.eu/en/healthtopics/ebola_marburg_fevers/ pages/index.aspx

2. World Health Organization (WHO). Ebola virus disease update West Africa. Geneva: WHO; 2014. Available from: http://www. who.int/csr/don/2014_08_06_ebola/en/ 